\title{
Assessment of ovarian function by clinical, hormonal and sonological parameters in post hysterectomy premenopausal women
}

\author{
G. D. Maiti ${ }^{1 *}$, Darshana Wayzade ${ }^{2}$, M. K. Tangri ${ }^{1}$, Shilpa Gupta ${ }^{1}$, Vibhu Chatterjee ${ }^{1}$
}

\begin{abstract}
${ }^{1}$ Department of Obstetrics and Gynecology, Command Hospital (EC), WBUHS, Kolkata, West Bengal, India
${ }^{2}$ Department of Obstetrics and Gynecology, Shatayu Multispeciality Hospital, Jalna, Maharashtra, India
\end{abstract}

Received: 01 March 2018

Accepted: 07 March 2018

*Correspondence:

Dr. G. D. Maiti,

E-mail: gdmaiti@rediffmail.com

Copyright: () the author(s), publisher and licensee Medip Academy. This is an open-access article distributed under the terms of the Creative Commons Attribution Non-Commercial License, which permits unrestricted non-commercial use, distribution, and reproduction in any medium, provided the original work is properly cited.

\begin{abstract}
Background: Hysterectomy with or without ovarian preservation is one of the common gynaecological major surgery performed worldwide. Ovarian function in future life therefore remains a contentious subject when ovaries are preserved. Assessment of ovarian function was done by clinical, hormonal and sonological parameters in post hysterectomy premenopausal women to assess, onset of menopausal symptoms, serum hormonal levels, and anatomical status.

Methods: The study was a prospective observational study of 110 premenopausal patients of 30 to 50 years of age undergoing hysterectomy for benign uterine conditions carried out from September 2014 to August 2016. Patients were followed up after operation at 3 months, 6 months and 1 year. Serum LH, serum FSH, serum Estrogen, bilateral ovarian volume and bilateral ovarian Doppler study were done at baseline and each visit. Patients were interviewed at each visit for menopausal symptoms. Menopausal Rating scale (MRS) questionnaire was used as a basis for assessing menopausal symptoms.

Results: Significant difference noted in all the parameters like serum FSH, right and left ovarian volume and right and left ovarian pulsatility index at period of one year compared to preoperative values. No significant difference seen for serum LH and serum estrogen at period of one year. At 1 year 34 patients (34\%) developed menopausal symptoms.

Conclusions: For all premenopausal patients who undergo hysterectomy for benign conditions of uterus with their ovaries preserved, proper follow up should be done after the surgery for assessing ovarian function at intervals.
\end{abstract}

Keywords: Estrogen, Hysterectomy, Menopausal symptoms, Ovarian function, Ovarian doppler, Ovarian volume

\section{INTRODUCTION}

Hysterectomy rate of $4-6 \%$ has been reported from survey in India, prevalence being more in women aged above 35 years maximum prevalence being in $45-54$ year age group. ${ }^{1,2}$

Traditionally, bilateral salpingo-oophorectomy used to be performed prophylactically to prevent ovarian cancer and to prevent potential for further surgery. It is evident that early menopause leads to all-cause morbidity., 3,4
Both the American College of Obstetrician and Gynecologists and the Society of Gynecologic Oncologists recommend ovarian conservation after careful risk assessment of ovarian cancer in patients undergoing hysterectomy for benign conditions who are at average risk of ovarian cancer (approximate lifetime risk of ovarian cancer: $1.4 \%) ., 6$

An unresolved concern with hysterectomy is whether it leads to accelerated loss of ovarian function. Ovarian function needs to be assessed in such patients so that 
hormone therapy and other preventive and curative measures can be considered in those who demonstrate loss of ovarian function.

Aim of the present study was, assessment of ovarian function by clinical, hormonal and sonological parameters in post hysterectomy premenopausal women. Objectives of present study were to assess the period of onset of menopausal symptoms after hysterectomy, to assess the changes in hormonal levels in blood after hysterectomy over a period of one year and to assess the changes in blood supply of ovaries and size of ovaries after hysterectomy.

\section{METHODS}

The present work is a prospective observational study of 110 premenopausal patients undergoing hysterectomy for benign uterine conditions, conducted in the Department of Obstetrics and Gynecology, a tertiary health care establishment. Study was carried out from September 2014 to August 2016. Voluntary informed consent was obtained from the subjects. The study protocol was approved by the local ethics committee.

Detailed menstrual and obstetric history, past history, family and personal history was documented from the patients. Thorough clinical examination and relevant blood and imaging investigations were done. Pap smear examination and endometrial biopsy was carried out in each case to confirm the benign nature of condition, final inclusion being subjected to the benign histopathological findings of the surgical specimen.

Baseline serum LH, FSH, Estrogen, bilateral ovarian volume and bilateral ovarian Doppler study (Pulsatility index) were done before surgery and at each follow up at 3 months, 6 months and 1 year.

Blood hormone levels by immunoradiometric assays were done after an overnight fast. All above investigations were carried out on day 2 or 3 of the cycle i.e. early follicular phase. After hysterectomy follicular phase was confirmed by absence of dominant follicle and absence of corpus luteum in bilateral ovaries by ultrasonography. ${ }^{7}$

Patients with FSH $>20$ IU/L at baseline were considered going into menopausal transition. Patients with $\mathrm{FSH}>40$ IU/L were considered menopausal.

Patients were interviewed at each visit for menopausal symptoms by using Menopausal Rating scale (MRS) questionnaire. 8

\section{Inclusion criteria}

Patients aged 30-50 years of age undergoing hysterectomy for benign conditions of uterus.

\section{Exclusion criteria}

- $\quad$ Patients with menopause (No menses for $>1$ year)

- Hysterectomy for malignant pathology

- Any previous surgery on ovary

- $\quad \mathrm{FSH}>20 \mathrm{IU} / \mathrm{L}$

- Patients with history of uterine artery embolization

- Chemotherapy or radiotherapy in the past

- History of smoking

- $\quad \mathrm{BMI}>30 \mathrm{Kg} / \mathrm{M}^{2}$

\section{RESULTS}

Total $100(90.9 \%)$ cases had completed the follow up. 10 $(9.1 \%)$ cases lost the follow up. Most Common age group was $45-49$ years $(50.0 \%)$.

Table 1: Comparison of serum FSH levels at different time intervals (Tukey Test).

\begin{tabular}{|lll|}
\hline Comparison pairs & Q-value & p-value \\
\hline Preoperative vs. 3 months & 4.648 & $\leq 0.05$ \\
\hline Preoperative vs. 6 months & 8.443 & $\leq 0.05$ \\
\hline Preoperative vs. 1 year & 11.077 & $\leq 0.05$ \\
\hline 3 months vs. 6 months & 3.796 & $\leq 0.05$ \\
\hline 3 months vs. 1 year & 6.429 & $\leq 0.05$ \\
\hline 6 months vs. 1 year & 2.634 & $>0.05$ \\
\hline
\end{tabular}

At 3 months, 6 months and at 1 year, $2(1.9 \%), 9(8.9 \%)$ and $20(20 \%)$ patients respectively had serum FSH greater than $20 \mathrm{IU} / \mathrm{L}$. At 3 months, 6 months and at 1 year, 0 $(0.0 \%), 2(1.9 \%)$ and $5(5 \%)$ patients respectively had serum FSH greater than 40 IU/L.

Table 2: Comparison of ovarian volume at various time intervals (Tukey Test).

\begin{tabular}{|c|c|c|}
\hline & Q-value & p-value \\
\hline \multicolumn{3}{|l|}{ Right ovary volume } \\
\hline Preoperative vs. 3 months & 9.489 & $\leq 0.05$ \\
\hline Preoperative vs. 6 months & 2.584 & $>0.05$ \\
\hline Preoperative vs. 1 year & 4.401 & $\leq 0.05$ \\
\hline 3 months vs. 6 months & 1.817 & $>0.05$ \\
\hline 3 months vs. 1 year & 6.905 & $\leq 0.05$ \\
\hline 6 months vs. 1 year & 5.088 & $\leq 0.05$ \\
\hline \multicolumn{3}{|l|}{ Leftt ovary volume } \\
\hline Preoperative vs. 3 months & 9.020 & $\leq 0.05$ \\
\hline Preoperative vs. 6 months & 3.179 & $>0.05$ \\
\hline Preoperative vs. 1 year & 6.397 & $\leq 0.05$ \\
\hline 3 months vs. 6 months & 5.841 & $\leq 0.05$ \\
\hline 3 months vs. 1 year & 3.219 & $>0.05$ \\
\hline 6 months vs. 1 year & 33.000 & 2.623 \\
\hline
\end{tabular}

Significant difference noted in parameters like serum FSH, right and left ovarian volume and right and left ovarian pulsatility index at period of one year compared to preoperative values. No significant difference seen for serum LH and serum estrogen at period of one year. 
Total $11(10 \%)$ patients had menopausal symptoms before the surgery. At 3 months, 6 months and at 1 year, $24(23.3 \%), 32(31.7 \%)$ and $34(34.0 \%)$ patients respectively developed menopausal symptoms. Overall somatic symptoms were present in 30 (30.0\%), psychological symptoms in $19(19.0 \%)$ and urogenital symptoms in $12(12.0 \%)$ patients at 1 year. When patients with or without menopausal symptoms were compared with the change in parameters at one year, significant difference was noted for FSH levels and ovarian volume. This difference was not found significant for all parameters.

\section{DISCUSSION}

The present findings are consistent with the long-standing hypothesis that women with hysterectomy experience the menopausal transition earlier as evidenced from the new onset of menopausal symptoms, increasing levels of serum FSH, increasing pulsatility index and decreasing ovarian volume.

Studies by Moorman PG et al, Ahn Eh et al, Chalmers C, Cooper GS et al and Siddle $\mathrm{N}$ indicate that the prevalence of ovarian failure is higher in women who undergo hysterectomy whereas studies by Bhattacharya et al; Dogan et al; Stone SC and Souza AZ et al report no decrease in ovarian function. ${ }^{9-17}$

Avanie $\mathrm{P}$ et al noted the most prevalent symptoms reported include from somatic/vasomotor subscale followed by psychological subscale and urogenital subscale. ${ }^{18}$ These results correspond to the result of this study for the similar age group (i.e. 40-50 years age group) which shows somatic, psychological and urogenital symptoms in $80 \%, 40 \%$ and $40 \%$ Vs. present study which shows $88.2 \%, 55.9 \%$ and $35.3 \%$ at 1 year follow up.

Pavlik et al and Kelsey TW et al observed a significant reduction in ovarian volume with each decade from age $25 .{ }^{19,20}$ Present study shows a natural trend of decreasing ovarian volume with age. It decreased significantly over the period of 1 year in our study suggesting that the natural process of decrease in the ovarian volume is hastened by the hysterectomy.

The strengths of our study include its prospective design. All the investigations were carried out in the follicular phase so that all the natural variability in above parameters can be avoided. As the study considers clinical, hormonal and sonological parameters together with their serial measurements, it gives the comprehensive knowledge and correlation of those parameters at a single glance.

There are some limitations of our study. FSH as a marker of ovarian function as it is pulsatile in nature, has no cutoff point that absolutely distinguishes pre-menopausal from postmenopausal women. ${ }^{21}$ Commonly used value of
FSH i.e. $40 \mathrm{IU} / \mathrm{L}$ is a very specific but less sensitive indicator of ovarian failure. There can be bias in the menopausal symptoms detection as it depends on the levels of understanding, awareness and education of the patients.

\section{CONCLUSION}

Thus for all premenopausal patients who undergo hysterectomy for benign conditions of uterus with their ovaries preserved, proper follow up should be done after the surgery for assessing ovarian function at intervals. This will help in adopting preventive and curative measures to tackle morbidities occurring because of loss of ovarian function. Patient should also be counseled about the possibility of loss of ovarian function even after preserving the bilateral ovaries and patient should be encouraged for further follow up after surgery for ovarian function assessment.

Funding: No funding sources

Conflict of interest: None declared

Ethical approval: Not required

\section{REFERENCES}

1. Singh AJ, Arora AK. Profile of menopausal women in rural north India. Climacteric. 2005 Jun;8(2):17784.

2. Singh A, Arora AK. Why hysterectomy rates are lower in India. Indian J Community Med. 2008 Jul;33(3):196-7.

3. Gallagher JC. Effect of early menopause on bone mineral density and fractures. Menopause. 2007 May-Jun;14(3 Pt 2):567-71.

4. Jacobsen BK, Heuch I, Kvale G. Age at natural menopause and all-cause mortality: a 37-year followup of 19,731 Norwegian women. Am J Epidemiol. 2003 May;157(10):923-9.

5. American College of Obstetricians and Gynecologists. ACOG Practice Bulletin No. 84. Elective and risk reducing salpingo-oophorectomy. Obstet Gynecol. 2008;111:231-41.

6. Berek JS, Chalas E, Edelson M. Prophylactic and risk reducing bilateral salpingo-oopherectomy: recommendations based on risk of ovarian cancer. Obstet Gynecol. 2010;116:1088-95.

7. Tinkanen H, Kujansuu E, Laippala $P$. The association between hormone levels and vascular resistance in uterine and ovarian arteries in spontaneous menstrual cycles: a Doppler ultrasound study. Acta Obstet Gynecol Scand. 1995 Apr;74(4):297-301.

8. Heinemann LAJ, Potthof FP, Schneider HP. International version of the menopause rating scale (MRS). Health Qual Life Outcomes. 2003;1:28.

9. Patricia GM, Evan RM, Joellen MS, Edwin SI, Frances W et al. Effect of Hysterectomy With Ovarian Preservation on Ovarian Function. Obstet Gynecol. 2011 December;118(6):1271-9. 
10. Ahn EH, Bai SW, Song CH. Effect of hysterectomy on conserved ovarian function. Yonsei Med J. 2002 Feb;43(1):53-8.

11. Chalmers C. Does hysterectomy in premenopausal woman affect ovarian function? Med Hypotheses. 1996 Jun;46(6):573-5.

12. Cooper GS, Thorp JM. FSH levels in relation to hysterectomy and to unilateral oophorectomy. Obstet Gynaecol. 1999 Dec;94(6):969-72.

13. Siddle N, Sarrel P, Whitehead M. The effect of hysterectomy on the age at ovarian failure: identification of a subgroup of women with premature loss of ovarian function and literature review. Fertil Steril. 1987 Jan;47(1):94-100.

14. Bhattacharya S, Mollison J, Pinion S. A comparison of bladder and ovarian function two years following hysterectomy or endometrial ablation. $\mathrm{Br} \mathrm{J}$ Obstet Gynaecol. 1996 Dec;103(12):898-903.

15. Dogan MM, Basaran Z, Ekici E. Effect of hysterectomy on ovarian blood supply and function. J Obstet Gynaecol. 1998;18:263-6.

16. Stone SC, Dickey RP, Mickal A. The acute effect of hysterectomy on ovarian function. Am J Obstet Gynecol. 1975 Jan;121(2):193-7.

17. Souza AZ, Fonseca AM, Izzo VM, Clauzet RM, Salvatore CA. Ovarian histology and function after total abdominal hysterectomy. Obstet Gynecol. 1986 Dec;68(6):847-9.

18. Avanie P, Deepali H, Subhash K. Assessment of menopausal symptoms in perimenopause and postmenopause women above 40 years in rural area. IJHBR. 2013;1(3):166-174.

19. Pavlik EJ, DePriest PD, Gallion HH. Ovarian volume related to age. Gynecol Oncol. 2000Jun; 77(3):410-2.

20. Kelsey TW, Wallace WHB. Ovarian volume correlates strongly with the number of nongrowing follicles in the human ovary. Obstet Gynecol Int. 2012;2012:1-5.

21. Backer LC, Rubin CS, Marcus M, Kieszak SM, Schober SE. Serum follicle-stimulating hormone and luteinizing hormone levels in women aged 35-60 in the U.S. population: the Third National Health and Nutrition Examination Survey (NHANES III, 19881994). Menopause. 1999;6(1):29-35.

Cite this article as: Maiti GD, Wayzade D, Tangri MK, Gupta S, Chatterjee V. Assessment of ovarian function by clinical, hormonal and sonological parameters in post hysterectomy premenopausal women. Int J Reprod Contracept Obstet Gynecol 2018;7:1376-9. 